\title{
REPEATABILITY ESTIMATES FOR SEMINAL TRAITS AND THEIR PHENOTYPIC RELATIONSHIPS WITH TESTES MEASUREMENTS AND PERFORMANCE TRAITS IN BLACK BENGAL BUCK
}

\author{
A. K. Rajuana ${ }^{1,2}$, M. R. Tayabur ${ }^{2}$, M. A. Hoque ${ }^{1}$, S. S. Husain ${ }^{1}$ and Z. Sultana ${ }^{2}$
}

\begin{abstract}
Repeatability for seminal traits and their phenotypic relationships with testes measurements and performance traits in Black Bengal bucks were estimated from a total of 116 repeated observations on 15 young Black Bengal bucks. Performance traits included age, body condition and body weight of bucks. Testes measurements were testes length, breadth and volume, and scrotal circumference, while seminal traits were ejaculate volume, semen density, mass activity, sperm motility, sperm concentration, total sperm per ejaculation and percent of normal sperm. High positive correlations (ranging from 0.81 to 0.90 ) were found between body weight and testes measurements. Semen volume and percent of normal sperm were positively correlated with age, body condition and body weight of bucks (ranging from 0.24 to 0.60 ). The testes measurements were strongly and positively correlated with semen volume and total sperm per ejaculation (ranging from 0.53 to 0.61 ), while the correlations between testes measurement and percent of normal sperm were moderate (ranging from 0.34 to 0.44 ). Among seminal traits, strong correlations were found between semen volume and total sperm per ejaculation (0.81) and, between mass activity and sperm motility (0.82). Repeatability of ejaculate volume was higher $(r=0.78)$ which indicated that selection or culling for semen ejaculate volume could be practiced from single or few observations. It could be concluded that bucks' age, body weight and body condition along with testes volume should be considered as selection criteria for improving semen quality and semen production of breeding bucks.
\end{abstract}

Key words : Testes measurements, Semen characteristics, Correlations, Repeatability

\section{Introduction}

Black Bengal goat occupies the second position for their contribution in the total livestock sector in Bangladesh. Small size of the animal is significant in respect of their economic, managerial and biological advantages. Increased production efficiency can be expected from goats resulting from high reproduction rate viz. increased litter size, shorter gestation interval and higher fertility. However, for better propagation of this species, there should have good breeding bucks. But there are severe shortfalls of stud bucks all over the country. Unlike cattle, goat raisers castrate almost all of male kids at the early age for economic and social

\footnotetext{
${ }^{1}$ Department of Animal Breeding and Genetics, Bangladesh Agricultural University, Mymensingh, Bangladesh

${ }^{2}$ Central Cattle Breeding and Dairy Farm, Savar, Dhaka, Bangladesh
}

(Reviewed : July 27, 2008) 
Bang. J. Anim. Sci. 2008, 37(2)

reason (Amin et al., 1998). Consequently, availability of breeding bucks became squeezed. Traditional people keep bucks of unknown pedigree and use them in service on charge. Therefore, there remains no chance for judging breeding soundness and fertility of the buck. Impetus towards genetic improvement has been absolutely ignored.

Artificial insemination program with known genetic merits of breeding bucks is vitally important. In artificial insemination, the genetic impact of a superior buck is determined by the number of does inseminated and this is limited by the number of sperm and quality of semen. However, before considering the sequences of events at insemination, an understanding of good quality semen is desirable (Hunter, 1985). The quality of semen in relation to fertility is determined by the volume of ejaculate, sperm concentration and motility, percent of live sperm and the sperm morphology. The knowledge on correlations of male reproductive traits among themselves and with other variables such as age, weight, body condition and testis size might have important bearings to indicate the real producing ability of a male for sperm output and quality of semen. Semen production of a breeding male is repeatable at high frequency in life. Repeatability estimates of seminal traits would help selection or culling of males on the basis of individual's records. It would also help in predicting most probable producing ability of a male for sperm output and semen quality. Considering the above facts, the present study was conducted to estimate repeatability of seminal traits and the correlations among seminal traits, testes measurements and performance traits on Black Bengal buck.

\section{Materials and Methods}

\section{Animals and data source}

Traits related to artificial insemination on 15 Black Bengal bucks were collected during the period from July 1995 to June 1996. The bucks were maintained at the Department of Surgery and Obstetrics, Bangladesh Agricultural University, Mymensingh. Feeding and management were more or less uniform throughout the year. Each buck was provided ad libitum access to green grass and fresh water. They also received a mixture of concentrate of about $0.5 \mathrm{~kg} /$ day. Concentrate feed includes maize, rice bran, wheat bran, fish meal, etc. Sometime the animals were grazed on the field under the supervision of a caretaker. All bucks were vaccinated against Peste des Petit Ruminant (PPR) and Tetanus. They were also de-wormed three times a year.

\section{Performance traits}

Age in months and body weight in kg for all the bucks were recorded. The individual bucks were weighed by weighing balance designed for small ruminants. The body condition score were estimated by visual estimation firstly, and then by feeling the back bone in the area between the back of the ribs and the front of the pelvic bone. This scoring was also performed by feeling the amount of muscle cover on the vertebra. The scale for scoring was from 1-5. 


\section{Testes measurement}

The length and breadth of two testes were measured biweekly from head of the epididymis to the tail of the epididymis by using measuring tape and the average value was calculated. The measurement for scrotal circumference was taken at the area of the broadest part of the scrotum using a special tape constructed for this purpose. By using average testes length and breadth, testes volume was estimated from the formula (Mohammed and Bhattacharja, 1987).

\section{Seminal traits}

Semen was collected from the bucks using an artificial vagina by the use of induced teaser. The internal temperature of the artificial vagina was about $45-50^{\circ} \mathrm{C}$, and it was lubricated with non-spermicidal gel. After collection, the semen and diluents remained at $35^{\circ} \mathrm{C}$ in a water bath until dilution was completed. The volume of semen was measured using a micropipette. The density was scored as 1 to $5(1=$ watery-cloudy, $2=$ milky, $3=$ thin creamy, 4 = creamy, and 5 = creamy-grainy). To evaluate mass activity (wave motion), a drop of semen was placed on a pre-warmed slide $\left(37^{\circ} \mathrm{C}\right)$ and examined under phase-contrast microscope. The mass activity was scored 1 to $5(1=$ no perceptible motion, $2=$ weak motion without forming any wave, $3=$ small, slow moving waves, $4=$ vigorous movement with moderately rapid waves and eddies, and $5=$ dense). The motility was determined at $\times$ 400 by subjective estimation of the proportion of sperm moving actively forward. The concentration of sperm was determined using a hemocytometer and the total number of sperm was calculated by multiplying the volume of ejaculate by the concentration. The morphology of sperm was evaluated after staining a thin smear with Williams's technique (Williams, 1920). At least 500 spermatozoa were examined.

\section{Statistical analysis}

Data were sorted and analyzed at the Department of Animal Breeding and Genetics of the same university. Data were analyzed with the general linear model (GLM) procedure using the computer software STATGRAF (ver. 7.0) according to the formula described by Steel and Torrie (1980). Repeatability estimates of seminal traits were estimated from intra-class correlation of repeated measurements within individuals (Becker, 1964). The model used to calculate repeatability was:

$$
\begin{aligned}
& \mathrm{Y}_{\mathrm{ij}}=\mu+\alpha_{\mathrm{i}}+\mathrm{e}_{\mathrm{ij}} \\
& \text { where, } \\
& \mathrm{Y}_{\mathrm{ij}}=\text { observation of the } \mathrm{j} \text {-th measurements on the } \mathrm{i} \text {-th individual } \\
& \mu=\text { overall mean } \\
& \alpha_{\mathrm{i}}=\text { individual effect } \\
& \mathrm{e}_{\mathrm{ij}}=\text { random error }
\end{aligned}
$$


Bang. J. Anim. Sci. 2008, 37(2)

\section{Results}

Some statistical parameters including means with standard deviations and coefficients of variation are presented in Table 1 . The variability of traits were a bit higher than $10 \%$ for testes length, breadth and circumference, while around 25 to $35 \%$ for bucks' age, weight, condition score, and testes volume. Variation in semen density, mass activity, sperm motility and percentage of normal sperm were about 15 to $25 \%$, and, of ejaculate volume, sperm concentration and total sperm per ejaculate were about 40 to $75 \%$.

Phenotypic correlations between performance traits and testes measurements are shown in Table 2. Moderate and positive phenotypic correlations of age and body condition score with testes measurements were observed $(0.45$ to 0.55$)$. Body weight of bucks were positively correlated with testes measurements $(0.81$ to 0.90$)$, which suggests that with the increase of age, live weight and body condition score of buck testes mass will linearly increased.

Phenotypic correlations between performance and seminal traits are presented in Table 3 . Age and body condition score of buck were positively and moderately correlated with percentage of normal sperm in the semen ( 0.32 and 0.42 , respectively). Body weight of buck moderately correlated with percentage of normal sperm $(0.42)$, and strongly correlated with ejaculate volume (0.60) and number of total sperm per ejaculate $(0.52)$.

Table 1. Basic statistics for performance traits, testes measurement and seminal traits

\begin{tabular}{|c|c|c|c|c|c|}
\hline Category & Traits & Unit & Mean & S.D. & C.V. \\
\hline \multirow{3}{*}{ Performance traits } & Age of buck & Month & 8.03 & 2.45 & 30.55 \\
\hline & Body condition & 1-5 scale & 2.94 & 0.73 & 24.84 \\
\hline & Body weight & $\mathrm{kg}$ & 12.0 & 4.21 & 35.00 \\
\hline \multirow{4}{*}{ Testes measurement } & Testes length & $\mathrm{cm}$ & 5.85 & 0.60 & 10.36 \\
\hline & Testes breadth & $\mathrm{cm}$ & 4.64 & 0.56 & 12.21 \\
\hline & Scrotal circumference & $\mathrm{cm}$ & 18.50 & 2.10 & 11.37 \\
\hline & Testis volume & $\mathrm{cm}^{3}$ & 68.44 & 24.12 & 35.24 \\
\hline \multirow{7}{*}{ Seminal traits } & Ejaculate volume & $\mu 1$ & 271.98 & 170.58 & 62.71 \\
\hline & Semen density & $1-5$ scale & 3.62 & 0.61 & 16.94 \\
\hline & Mass activity & $1-5$ scale & 3.47 & 0.90 & 26.15 \\
\hline & Sperm motility & $\%$ & 73.87 & 18.34 & 24.83 \\
\hline & Sperm concentration & $\mathrm{mill} / \mathrm{ml}$ & 3778 & 1548 & 40.96 \\
\hline & Total sperm/ejaculate & mill & 1007 & 7.58 & 75.29 \\
\hline & Normal sperm & $\%$ & 85.78 & 16.80 & 19.58 \\
\hline
\end{tabular}

S.D, standard deviation; C.V., coefficient of variation 
Table 2. Phenotypic correlations between performance traits and testes measurements

\begin{tabular}{|l|c|c|c|c|}
\hline \multicolumn{1}{|c|}{ Traits } & Testes length & Testes breadth & Scrotal circumference & Testes volume \\
\hline Age & $0.44^{* * *}$ & $0.51^{* * *}$ & $0.50^{* * *}$ & $0.48^{* * *}$ \\
Body condition & $0.46^{* * *}$ & $0.53^{* * *}$ & $0.55^{* * *}$ & $0.49^{* * *}$ \\
Body weight & $0.81^{* * *}$ & $0.90^{* * *}$ & $0.90^{* * *}$ & $0.89^{* * *}$ \\
\hline
\end{tabular}

${ }^{* * *}, \mathrm{P}<0.001$

Table 3. Phenotypic correlations between performance traits and seminal traits

\begin{tabular}{|l|c|c|c|c|c|c|c|}
\hline \multirow{2}{*}{ Performance traits } & \multicolumn{7}{|c|}{ Seminal traits } \\
\cline { 2 - 9 } & $\begin{array}{c}\text { Ejaculate } \\
\text { volume }\end{array}$ & $\begin{array}{c}\text { Semen } \\
\text { density }\end{array}$ & $\begin{array}{c}\text { Mass } \\
\text { activity }\end{array}$ & $\begin{array}{c}\text { Sperm } \\
\text { motility }\end{array}$ & $\begin{array}{c}\text { Sperm } \\
\text { concentration }\end{array}$ & $\begin{array}{c}\text { Total } \\
\text { sperm }\end{array}$ & $\begin{array}{c}\text { Normal } \\
\text { sperm }\end{array}$ \\
\hline Age & $0.24^{* * *}$ & $0.27^{* *}$ & 0.10 & $0.17^{*}$ & 0.06 & $0.23^{* *}$ & $0.32^{* * *}$ \\
Body condition & $0.25^{* * *}$ & 009 & $0.26^{* *}$ & $0.32^{* * *}$ & -0.16 & 0.13 & $0.42^{* * *}$ \\
Body weight & $0.60^{* * *}$ & $0.21^{* *}$ & 0.07 & 0.11 & -0.04 & $0.52^{* * *}$ & $0.42^{* * *}$ \\
\hline
\end{tabular}

${ }^{*}, \mathrm{P}<0.05 ;{ }^{* *}, \mathrm{P}<0.01 ;{ }^{* * *}, \mathrm{P}<0.001$

The phenotypic correlation between testes measurements and seminal traits are shown in Table 4. Testes measurements showed strong positive relationships with ejaculate volume (ranging from 0.60 to 0.65 ) and number of total sperm per ejaculation (ranging from 0.53 to $0.58)$. The observed relationships indicated that testes volume estimated from testes length and breadth could fairly represent the other testes measurement (i.e., testes length and breadth).

Table 4. Phenotypic correlations between testes measurements and seminal traits

\begin{tabular}{|l|c|c|c|c|c|c|c|}
\hline \multirow{2}{*}{$\begin{array}{c}\text { Testes } \\
\text { measurements }\end{array}$} & \multicolumn{7}{|c|}{ Seminal traits } \\
\cline { 2 - 8 } & $\begin{array}{c}\text { Ejaculate } \\
\text { volume }\end{array}$ & $\begin{array}{c}\text { Semen } \\
\text { density }\end{array}$ & $\begin{array}{c}\text { Mass } \\
\text { activity }\end{array}$ & $\begin{array}{c}\text { Sperm } \\
\text { motility }\end{array}$ & $\begin{array}{c}\text { Sperm } \\
\text { concentration }\end{array}$ & $\begin{array}{c}\text { Total } \\
\text { sperm }\end{array}$ & $\begin{array}{c}\text { Normal } \\
\text { sperm }\end{array}$ \\
\hline $\begin{array}{l}\text { Testes length } \\
\text { Testes breadth }\end{array}$ & $0.60^{* * *}$ & $0.16^{*}$ & 0.13 & 0.15 & -0.09 & $0.53^{* * *}$ & $0.37^{* * *}$ \\
$\begin{array}{l}\text { Scrotal } \\
\text { circumference }\end{array}$ & $0.21^{*}$ & 0.07 & 0.11 & 0.01 & $0.57^{* * *}$ & $0.37^{* * *}$ \\
Testes volume & $0.61^{* * *}$ & $0.23^{* *}$ & 0.12 & 0.14 & -0.01 & $0.58^{* * *}$ & $0.44^{* * *}$ \\
\hline
\end{tabular}

${ }^{*}, \mathrm{P}<0.05 ;{ }^{* *}, \mathrm{P}<0.01 ;{ }^{* * *}, \mathrm{P}<0.001$

Repeatability estimates for and interrelationships among seminal traits are summarized in Table 5. Repeatability estimates i.e., the intra-class correlations among the repeated observations of semen characteristics within individual buck were found to be high (0.78) for ejaculate volume, moderate for total sperm per ejaculate $(0.30)$, and low for other seminal traits (ranging from 0.01 to 0.21 ). Ejaculate volume showed positive and strong correlation 
Bang. J. Anim. Sci. 2008, 37(2)

with total sperm ejaculate $(0.81)$, and moderate correlation with percentage of normal sperm (0.33). Strong correlations and initial mass activity with sperm motility $(0.82)$, and moderate correlations total sperm per ejaculate (0.33) and percentage of normal sperm (0.41). Moderate correlation was also found between ejaculate sperm motility and percentage of normal sperm (0.46).

Table 5. Repeatability ( \pm s.e.) (on the diagonal) for and interrelationships (above the diagonal) among seminal traits

\begin{tabular}{|l|c|c|c|c|c|c|c|}
\hline \multicolumn{1}{|c}{ Seminal traits } & $\begin{array}{c}\text { Semen } \\
\text { volume }\end{array}$ & $\begin{array}{c}\text { Semen } \\
\text { density }\end{array}$ & $\begin{array}{c}\text { Mass } \\
\text { activity }\end{array}$ & $\begin{array}{c}\text { Sperm } \\
\text { motility }\end{array}$ & $\begin{array}{c}\text { Sperm } \\
\text { concentration }\end{array}$ & $\begin{array}{c}\text { Total } \\
\text { sperm }\end{array}$ & $\begin{array}{c}\text { Normal } \\
\text { sperm }\end{array}$ \\
\hline Semen volume & $0.78 \pm 0.07$ & 0.12 & -0.01 & 0.04 & -0.06 & $0.81^{* * *}$ & $0.33^{* * *}$ \\
Semen density & - & $0.12 \pm 0.08$ & -0.03 & -0.03 & $0.50^{* * *}$ & $0.33^{* * *}$ & 0.08 \\
Mass activity & - & - & $0.18 \pm 0.09$ & $0.82^{* * *}$ & -0.09 & -0.07 & $0.41^{* * *}$ \\
Sperm motility & - & - & - & $0.21 \pm 0.10$ & 0.07 & -0.03 & $0.46^{* * *}$ \\
Sperm & - & - & - & - & $0.01 \pm 0.05$ & $0.44^{* * *}$ & $-0.19^{*}$ \\
concentration & - & - & - & - & - & $0.30 \pm 0.11$ & $0.18^{*}$ \\
Total sperm & - & - & - & - & - & & $0.20 \pm 0.09$ \\
Normal sperm & - & - & - & - & & &
\end{tabular}

\section{Discussion}

The average values for testes measurements and seminal traits were in agreement with the results by several researchers (Birgel et al., 1993; Azevedo et al., 1995; Bakshi et al., 1987). Increased variation observed in body weight in the present study might be due to age variation of the experimental animals. Estimated high variation in testes volume was caused by the scale effects of squared transformation of length and breadth in estimating the testes volume. Higher variations in ejaculate volume, sperm concentration and total sperm per ejaculate might be due to the age and individual performance differences of the buck. Lasley (1978) noted that causes of phenotypic variation in traits of farm animals are the hereditary, environment and the joint effect of hereditary and environment.

Estimated high positive correlations between body weight and testes measurements indicated that testes measurements were strongly associated with age, body condition score and especially with body weights. Bucks' age, body weight and body condition score were found to be positively correlated with ejaculate volume, semen density, total sperm and percentage of normal sperm, which were in agreement with the findings of Colas (1976). Since body weight and testes volume were positively correlated with semen production, both of these parameters could serve as the criteria for selection of valuable bucks. In lacking of information on age and weight of bucks, testes length, breadth and circumference should be given in to consideration. In general, selecting young bucks for mating purposes, age, body weight, body condition score, and testes measurements could jointly be taken as important 
criteria for selection. Interrelationships of seminal traits were found to be positive among ejaculate volume, total sperm per ejaculation and percentage of normal sperm.

The high repeatability estimate for ejaculate volume was in agreement with the estimate reported by Dalton (1990), who reviewed the repeatability estimates of published studies and noted that the estimate for semen volume per ejaculate as 0.70 to 0.78 . High repeatability estimate for ejaculate volume indicated that bucks' real producing ability could be estimated from a single or a few observations. Dhillon et al. (1975) estimated low repeatability estimates for semen density (0.21), sperm concentration (0.35), percent of normal sperm (0.31), and mass activity of sperm (0.18), which supports the present results. Langford (1989) found repeatability for total sperm per ejaculate as 0.50 , which was slightly higher than the present study. Repeatability estimates for most of the seminal traits observed to be low, which indicate that these traits are much affected by temporary environmental influences.

\section{Conclusion}

Significant variations between individual bucks were observed in body condition score, body weight, testes measurements and seminal traits, except sperm concentration. Strong positive correlations were found between body weight and testes measurements. These two traits were also found to be positively correlated with most of the seminal traits. In selecting breeding bucks, body weight and testes volume should be considered as selection criteria for improving seminal performance.

\section{Literature Cited}

Azevedo, J., Valentim, R., Silva, S. and Correla, T. M. 1995. Relation between in-vivo testis and scrotal measurements and post-mortem testis volume and weight in Serrana goat. Veterinaria Tecnica, Portugal. 5 : 10-13.

Bakshi, S. A., Patil, V. K., Srivas, A. K., Jagtap, D. Z. and More, B. K. 1987. Studies on semen evaluation and fertility rate of Angora and $7 / 8$ Angora bucks. Livest. Advis. 12 : 13-18.

Becker, W. A. 1964. Manual of procedures in quantitative genetics. Third Edition. Washington State University, Pullman, Washington. pp. 4-5.

Birgel, E. H., Vilar, A. C., Barnabe, V. H., Visintin, J. A. and Barnabe, R. C. 1993. Testes and semen characters in goats reared in a semi-arid environment in Paraiba State. Revista Brasileira de Reproducao Anim. Brazil. 17 : 23-32.

Colas, G. 1976. Semen production and testicular development in Ile-de France and Prealpes lambs. Anim. Breed. Abstr. $44: 364$.

Dalton, D. C. 1980. An introduction to practical animal breeding. Granada Publishing Limited. Britain. pp. 65-67.

Dhillon, J. S., Acharya, R. M. and Singh, R. N. 1975. Repeatability of semen characteristics in rams. Ind. J. Anim. Sci. 15: 594-595. 
Bang. J. Anim. Sci. 2008, 37(2)

Hunter, R. H. F. 1985. Reproduction in farm animals. $3^{\text {rd }}$ edition. Longman. pp. 21-22.

Husain, S. S., Amin, M.R. and Islam, A. B. M. M. 1998. Goat production and its breeding strategy in Bangladesh. First National Workshop Report on Animal Breeding. Department of Animal Breeding and Genetics, Bangladesh Agricultural University, Mymensingh. pp. 22

Langford, G. A., Shrestha, S. A. and Marcus, G. J. 1989. Repeatability of scrotal size and semen quality measurements in rams in a short-day regime. Anim. Prod. Sci. 19 : 19-27.

Lasley, J. F. 1978. Genetics of Livestock Improvement. Prentice-Hill Inc., Englewood Cliffs, New Jersey. pp. 145-156.

Mohammad, K. and Bhattacharja, P. K. 1987. Integral calculus. Tawakkal Press. Lokkhibazar, Dhaka. pp. 211-212.

Steel, R. G. D. and Torrie, J. H. 1980. Principles and procedures of statistics with special reference to the biological science. McGraw-Hill Book Company. INC. New York.

Williams, W. W. 1920. Technique of collecting semen for laboratory examination with a review of several diseased bulls. Cornell Vet. 10 : 87-94. 